\title{
SOME INEQUALITIES FOR THE GENERALIZED $k-g$-FRACTIONAL INTEGRALS OF CONVEX FUNCTIONS
}

\section{Silvestru SEVER Dragomir}

Abstract. Let $g$ be a strictly increasing function on $(a, b)$, having a continuous derivative $g^{\prime}$ on $(a, b)$. For the Lebesgue integrable function $f:(a, b) \rightarrow \mathbb{C}$, we define the $k$ - $g$-left-sided fractional integral of $f$ by

$$
S_{k, g, a+} f(x)=\int_{a}^{x} k(g(x)-g(t)) g^{\prime}(t) f(t) d t, x \in(a, b]
$$

and the $k$ - $g$-right-sided fractional integral of $f$ by

$$
S_{k, g, b-} f(x)=\int_{x}^{b} k(g(t)-g(x)) g^{\prime}(t) f(t) d t, x \in[a, b),
$$

where the kernel $k$ is defined either on $(0, \infty)$ or on $[0, \infty)$ with complex values and integrable on any finite subinterval.

In this paper we establish some trapezoid and Ostrowski type inequalities for the $k-g$ fractional integrals of convex functions. Applications for Hermite-Hadamard type inequalities for generalized $g$-means and examples for Riemann-Liouville and exponential fractional integrals are also given.

Mathematics subject classification (2010): 26D15, 26A51, 26D07, 26A33.

Keywords and phrases: Generalized Riemann-Liouville fractional integrals, Hadamard fractional integrals, functions of bounded variation, Ostrowski type inequalities, trapezoid inequalities.

\section{REFERENCES}

[1] R. P. Agarwal, M.-J. Luo And R. K. Raina, On Ostrowski type inequalities, Fasc. Math. 56 (2016), 5-27.

[2] A. Aglić Aluinović, Montgomery identity and Ostrowski type inequalities for Riemann-Liouville fractional integral, J. Math.2014, Art. ID 503195, 6 pp.

[3] T. M. Apostol, Mathematical Analysis, Second Edition, Addison-Wesley Publishing Company, 1975.

[4] A. O. AKDEMIR, Inequalities of Ostrowski's type for $m$ - and $(\alpha, m)$-logarithmically convex functions via Riemann-Liouville fractional integrals, J. Comput. Anal. Appl. 16 (2014), no. 2, 375-383.

[5] G. A. Anastassiou, Fractional representation formulae under initial conditions and fractional Ostrowski type inequalities, Demonstr. Math. 48 (2015), no. 3, 357-378.

[6] G. A. Anastassiou, The reduction method in fractional calculus and fractional Ostrowski type inequalities, Indian J. Math. 56 (2014), no. 3, 333-357.

[7] H. BudAK, M. Z. SARIKAYA, E. SeT, Generalized Ostrowski type inequalities for functions whose local fractional derivatives are generalized s-convex in the second sense, J. Appl. Math. Comput. Mech. 15(2016), no. 4, 11-21.

[8] P. CERone AND S. S. Dragomir, Midpoint-type rules from an inequalities point of view, Handbook of analytic-computational methods in applied mathematics, 135-200, Chapman \& Hall/CRC, Boca Raton, FL, 2000.

[9] S. S. DragomiR, The Ostrowski's integral inequality for Lipschitzian mappings and applications, Comput. Math. Appl. 38 (1999), no. 11-12, 33-37. 
[10] S. S. Dragomir, The Ostrowski integral inequality for mappings of bounded variation, Bull. Austral. Math. Soc. 60 (1999), No. 3, 495-508.

[11] S. S. DRAGOMIR, On the midpoint quadrature formula for mappings with bounded variation and applications, Kragujevac J. Math. 22 (2000), 13-19.

[12] S. S. Dragomir, On the Ostrowski's integral inequality for mappings with bounded variation and applications, Math. Ineq. Appl. 4 (2001), No. 1, 59-66. Preprint: RGMIA Res. Rep. Coll. 2 (1999), Art. 7, [Online: http://rgmia.org/papers/v2n1/v2n1-7.pdf].

[13] S. S. DraGomir, Refinements of the generalised trapezoid and Ostrowski inequalities for functions of bounded variation, Arch. Math. (Basel) 91 (2008), no. 5, 450-460.

[14] S. S. Dragomir, Refinements of the Ostrowski inequality in terms of the cumulative variation and applications, Analysis (Berlin) 34 (2014), No. 2, 223-240. Preprint: RGMIA Res. Rep. Coll. 16 (2013), Art. 29 [Online:http://rgmia.org/papers/v16/v16a29.pdf].

[15] S. S. Dragomir, Ostrowski type inequalities for Lebesgue integral: a survey of recent results, Australian J. Math. Anal. Appl. Volume 14, Issue 1, Article 1, pp. 1-287, 2017. [Online http://ajmaa.org/cgi-bin/paper.pl?string=v14n1/V14I1P1.tex].

[16] S. S. Dragomir, Ostrowski type inequalities for Riemann-Liouville fractional integrals of bounded variation, Hölder and Lipschitzian functions, Preprint RGMIA Res. Rep. Coll. 20 (2017), Art. 48. [Online http://rgmia.org/papers/v20/v20a48.pdf].

[17] S. S. DRAGomir, Ostrowski and trapezoid type inequalities for Riemann-Liouville fractional integrals of absolutely continuous functions with bounded derivatives, RGMIA Res. Rep. Coll. 20 (2017), Art. 53. [Online http://rgmia.org/papers/v20/v20a53.pdf].

[18] S. S. Dragomir, Ostrowski type inequalities for generalized Riemann-Liouville fractional integrals of functions with bounded variation, RGMIA Res. Rep. Coll. 20 (2017), Art. 58. [Online http://rgmia.org/papers/v20/v20a58.pdf].

[19] S. S. DRAGOMIR, Further Ostrowski and trapezoid type inequalities for the generalized RiemannLiouville fractional integrals of functions with bounded variation, RGMIA Res. Rep. Coll. 20 (2017), Art. 84. [Online http://rgmia.org/papers/v20/v20a84.pdf].

[20] S. S. DRAGomir, Some inequalities for the generalized $k$ - $g$-fractional integrals of functions under complex boundedness conditions, RGMIA Res. Rep. Coll. 20 (2017), Art. 119. [Online http://rgmia.org/papers/v20/v20a119.pdf].

[21] A. Guezane-Lakoud and F. Aissaoui, New fractional inequalities of Ostrowski type, Transylv. J. Math. Mech. 5 (2013), no. 2, 103-106.

[22] A. KASHURI AND R. LiKO, Ostrowski type fractional integral inequalities for generalized $(s, m, \varphi)$ preinvex functions, Aust. J. Math. Anal. Appl. 13 (2016), no. 1, Art. 16, 11 pp.

[23] A. Kilbas, H. M. Srivastava And J. J. Trujillo, Theory and Applications of Fractional Differential Equations, North-Holland Mathematics Studies, 204. Elsevier Science B.V., Amsterdam, 2006. xvi+523 pp. ISBN: 978-0-444-51832-3; 0-444-51832-0.

[24] M. Kirane, B. T. TorebeK, Hermite-Hadamard, Hermite-Hadamard-Fejer, DragomirAgarwal and Pachpatte type Inequalities for convex functions via fractional integrals, Preprint arXiv:1701.00092.

[25] M. A. Noor, K. I. Noor And S. Iftikhar, Fractional Ostrowski inequalities for harmonic $h$ preinvex functions, Facta Univ. Ser. Math. Inform. 31 (2016), no. 2, 417-445.

[26] R. K. RAINA, On generalized Wright's hypergeometric functions and fractional calculus operators, East Asian Math. J., 21(2)(2005), 191-203.

[27] M. Z. SARIKAYA AND H. FILIZ, Note on the Ostrowski type inequalities for fractional integrals, Vietnam J. Math. 42 (2014), no. 2, 187-190.

[28] M. Z. SARIKAYA AND H. BUDAK, Generalized Ostrowski type inequalities for local fractional integrals, Proc. Amer. Math. Soc. 145 (2017), no. 4, 1527-1538.

[29] E. SET, New inequalities of Ostrowski type for mappings whose derivatives are s-convex in the second sense via fractional integrals, Comput. Math. Appl. 63 (2012), no. 7, 1147-1154.

[30] M. Tunç, On new inequalities for h-convex functions via Riemann-Liouville fractional integration, Filomat 27:4 (2013), 559-565.

[31] M. TunÇ, Ostrowski type inequalities for $m$ - and $(\alpha, m)$-geometrically convex functions via Riemann-Louville fractional integrals, Afr. Mat. 27 (2016), no. 5-6, 841-850.

[32] H. YILDIRIM AND Z. KIRTAY, Ostrowski inequality for generalized fractional integral and related inequalities, Malaya J. Mat., 2(3)(2014), 322-329. 
[33] C. Yildiz, E, ÖZdemir and Z. S. Muhamet, New generalizations of Ostrowski-like type inequalities for fractional integrals, Kyungpook Math. J. 56 (2016), no. 1, 161-172.

[34] H. YUE, Ostrowski inequality for fractional integrals and related fractional inequalities, Transylv. J. Math. Mech. 5 (2013), no. 1, 85-89. 